\title{
Carolan, Michael, Cheaponomics: The High Cost of Low Prices, Londres e Nova Iorque: Routledge, 2014.
}

\author{
Recensão de Sofia Araújo \\ ILCML/ CETAPS/ Universidade do Porto
}

Michael Carolan é um sociólogo nascido em Fort Atkinson, no Iowa (E.U.A.), nas palavras do próprio não numa quinta, mas numa das maiores hortas caseiras do país. 0 enfoque primordial da sua investigação é a alimentação e as questões da sustentabilidade, mas através delas tem vindo a delinear uma teoria sociológica mais ampla de análise de (e combate a) aquilo que denomina "Cheaponomics" - uma subversão total e perniciosa do conceito de socialismo através da colectivização dos custos. Para Carolan a pergunta contemporânea fundamental é "Quem paga quando eu pago?" e não hesita em qualificar a sua obra mais geral como "quest to unveil chaponomics and its unsustainable costs" (2014: 129).

Ao longo da última década, a obra deste sociólogo regista um movimento de ida e volta entre os Food Studies e a constituição de uma leitura completa de uma contemporaneidade socio-económica que ele caracteriza pela antítese de qualquer forma de responsabilidade (cf. 2014: 3). A análise das questões alimentares permite-lhe, simultaneamente, comprovar, exemplificar e intuir as roldanas do sistema que pretende denunciar e dos custos ditos externalizados. Nesta viagem intelectual, poderemos marcar 
como partida 2010 com a publicação de Decentering Biotechnology: Assemblages Built and Assemblages Masked e A Sociological Look at Biofuels: Understanding the Past, livros em que profundas preocupações com a biologia e o confronto com o conceito convencional de propriedade e a comodificação da Natureza (ex. patentes de sementes) abrem a porta para a teoria sociológica que norteará os anos seguintes e que se desenvolve continuamente até No One Eats Alone: Food as a Social Enterprise (9 maio 2017). Carolan é um autor polifacetado que reúne sob uma preocupação central os contributos de múltiplas áreas do conhecimento e da reflexão humanos. Assim, quando em 2011 publica Embodied Food Politics aplica à ponderação das materializações da política alimentar o conceito de "embodied knowledge", comum em distintas áreas das ciências sociais, desde os estudos feministas à geografia crítica, desde a fenomenologia por si só às relações físicas, sensuais, corporizadas na/com a produção alimentar. No entanto, para lá do ângulo filosófico nunca descurado, Carolan tem objetivos que se vão tornando verdadeiramente programáticos de denúncia do estado das coisas e de proposta de alternativas. Assim, também em 2011 publica The Real Cost of Cheap Food no qual alia a exploração factual dos traços económicos e sociológicos da situação alimentar mundial a uma ponderação do papel histórico, político e civilizacional da comida. Neste livro denuncia o excessivo custo (oculto) do sistema alimentar globalizado, em termos de protecção do ambiente, da saúde humana e da biodiversidade, numa espécie de versão temática daquilo que virá a ser a sua análise da contemporaneidade total em Cheaponomics. Já em 2011 o tom é claramente programático e de ruptura na proposta de soluções, querendo ir além das habituais soluções bottom-up (agricultura comunitária, mercados de produtores, jardins e hortas comunitárias) para intervenção política sistematizada, apontando hipóteses como a promoção do microcrédito, os subsídios ao consumidor e a democratização dos subsídios ao produtor, sem esquecer soluções inovadoras no micro-plano, como a agricultura vertical. Até 2014, livros como The Sociology of Food and Agriculture (2012), Reclaiming Food Security (2013) e Society and the Environment: Pragmatic Solutions to Ecological Issues (2013) são fundamentais para o desenvolvimento da reflexão macro que avança na denúncia da insustentabilidade destrutiva da pechincha artificialmente criada que faz em Cheaponomics: The High Cost of 
Low Prices (2014), no qual concluirá pela apresentação de dez medidas possíveis pela Humanidade. A par com a leitura de Cheaponomics, é de todo o interesse também, aliás, Poisoned Planet, de Julian Cribb, também de 2014, que discute o prisma ambiental das escolhas sócio-económicas contemporâneas.

O percurso intelectual e activista de Michael S. Carolan continua neste rumo. Em 2015 tem um primeiro olhar para os Estudos sobre a Utopia - e mesmo para os Estudos Literários - quando é co-organizador de Food Utopias: Reimagining citizenship, ethics and community (2015), que inclui múltiplos ensaios de académicos diversos, com destaque para "Everyday Life in Utopia: Food, de Lyman Tower Sargent, e, do próprio Carolan, "Rewilding Food Systems: Visceralities, Utopias, Pragmatism, and Practice”. Neste artigo, para lá de questionar a própria ontologia de "alimento", Carolan toca na importância das utopias como consciencializadoras do cariz temporal das percepções alimentares, voltando a incorporar no seu discurso analítico as Embodied Food Politics. Um ano mais tarde retorna a muitas das questões da sociologia da agricultura de que partiu em 2010, co-organizando Biological Economies: Experimentation and the politics of agri-food frontiers (2016). Em 2017 publica No One Eats Alone: Food as a Social Enterprise, retornando o enfoque da sua denúncia da "Cheaponomics" ao campo alimentar, abordando tópicos intrínsecos às relações alimentares, incluindo a fome, a obesidade, os pesticidas tóxicos, a resistência a antibióticos, as deprimidas economias rurais e a depauperação laboral.

Cheaponomics: The Real Cost of Low Prices (2014) é o momento no qual Carolan explora a sua leitura sócio-económica do panorama contemporâneo para lá das fronteiras do caso de estudo alimentar que foi (e continuará a ser) primordial na sua obra académica. Aliás, é mesmo no uso das "calorias baratas" como forma de manter activa e mal-paga uma força laboral de multidões que encontra uma possível raiz da economia do falsamente barato (cf. 2015: 4). É um livro sustentado por sólida investigação académica (não apenas sociológica e económica, mas estendida a todos os diálogos laterais pertinentes, desde as neurociências dos testes de Emory aos estudos médicos de Michael Goran) e alicerçado na divulgação de estudos e elementos factuais, desde o modelo Kellogs de 1930 aos dramas e cinismo das cidades-lixeira como Guiyu, do Coltan (minerais de conflito) e dos clean rooms 
de Silicon Valley em que os chips são protegidos a expensas da saúde dos trabalhadores. Pretende, no entanto, ser igualmente um manifesto que projecta o futuro numa concepção, na linha de Joseph Stiglitz, de que o acesso total à informação conduzirá a que o consumidor faça escolhas mais inteligentes. 0 tom apelativo e provocador é patente em títulos de capítulos como "Real Prosperity is Priceless" e "You Bought that Computer but Someone Else Paid for It", mas importa assinalar que a acessibilidade não denuncia qualquer superficialidade ou facilitismo. Na linha de Ortega, aqui a clareza é (tão-só) a cortesia do pensador - uma clareza que se torna indispensável quando há o claro desejo de ser mote de acção. A denúncia académica de factores como a planificação de rápida obsolência de bens caracterizada pela Moore"s Law de 1965 e a sua associação a marcas históricas de fundação da identidade autónoma americana, por oposição à antiguidade europeia (cf. 2014: 46) é uma informação académica cuidadosamente estudada, mas é também alvo de um juízo de valor. Carolan não teme tomar partido - teme apenas a falta de sustentação das afirmações e das práticas, assegurando o papel interventivo do conhecimento. Quando divulga as conclusões de Richard Clapp em torno dos efeitos da exploração laboral promovida pela IBM, divulga também todo o emaranhar de campanhas de desinformação e manobras legais contra a investigação, usando o exemplo, e outros mais, como paradigmas da importância fulcral da independência académica (cf. 2014: 26-7) e de instituições de intervenção sustentada como o grupo Students and Scholars Against Corporate Misbehavior (SACOM). Estamos perante um livro científico E político - uma coisa gera a outra, porque para Carolan o reconhecimento dos padrões da realidade actual só pode impelir à acção.

A obra divide-se em três partes: Parte 1: Cheap Stuff, na qual aborda os consumos tecnológicos e os tidos por imateriais/intangíveis na era digital, os bens de uso efémero e custo desmesurado (ex. sacos de plástico) e a alimentação de baixo custo; Parte 2: Cheap Economies and Communities, em que o espectro de análise - recorrendo a questões concretas como os transportes, a concentração comercial e os sistemas laborais - se alarga às macro-estruturas económico-sociais; Parte 3: Transitioning towards Affordability - fase final na qual as grandes teorias coevas são confrontadas e Carolan aponta recomendações, discute hipóteses e os seus matizes - como o consumo colaborativo - e escolhe rumos. 
Logo na introdução, - "Free enterprise, socialism, and cheaponomics" - Carolan é completamente explícito quanto ao intuito político que tem, procurando extrair acção da responsabilidade gerada no leitor pelo conhecimento que adquire na obra:

Rather than temporary insanity, then, I think we can plead ignorance. But that does not reduce our level of blame. The benefit of being ignorant - over insane - is that you can actually change that state. Though to do this will require a collective rolling up of our sleeves. (2014: 7)

Há, no entanto, toda uma precaução notória de um autor que sabe que fala directamente para um público ocidental e maioritariamente norte-americano. Se é arrojado na denúncia da subversão ideológica de um socialismo invertido pelo capitalismo neoliberal, tem o cuidado de deixar muito explícito o desejo de melhor e não mais governo (cf. 2014: 38) e de manter a aposta tradicional na comunidade local. O próprio uso do termo "socialismo" não é de todo inadvertido, e Carolan presta especial atenção à substituição do eufemístico "externalidade de custo" por "socialização do custo", como estratégia para enfatizar que quando quem paga esse custo dito externo é o ambiente, outra população ou uma geração futura, esse não é um custo externo e diz respeito a todos neste que Carolan não hesita em denominar de "dog-eat-dog style of economics" (2014: 45). Fá-lo com plena consciência da complexidade de um mundo em rede onde tanto se pode importar abelhas para equilibrar ecossistemas (cf. 2014: 82) como se institui padrões de vida profundamente desiguais (cf. 2014: 97 - leis da qualidade do ar, a título de exemplo). Há, no entanto, um profundo humanismo na complexa leitura do Real, que tanto denuncia o potencial opressor de medidas que desejavam ser progressistas como compreende os fenómenos inultrapassáveis dos consumos distintivos ou das tentativas ilusórias, como a reciclagem como solução final ou a salvação de elefantes pela superação do marfim pelo plástico. Com este olhar crítico, não hesita em denunciar, com Douglas Kysar, a "tirania do presente" e dos loucos ciclos de produção ao estilo Uniqlo e em enfatizar a importância fundamental da regulação, para lá das estritas análises custo-benefício ao estilo míope de Reagan e Thatcher (cf. 2014: 51ss; 67) e dos (ab)usos de políticas públicas, como nos subsídios a produtores de químicos para a agricultura (cf. 2014: 68) ou na leitura que faz da CAP (cf. 2014: 71). A 
transição da ideia de "custo" para "valor" é difícil, porque não quantificável, mas fundamental, e Carolan está particularmente atento a todas as questões sociais da actualidade, desde os refugiados climáticos à descriminação ambiental, do consumo colaborativo aos boicotes inversos (carrotmobs). Como afirma, "When we reduce human life to statistical terms we deny people the dignity to be thought of as humans. Similarly, by putting a price tag on ecosystems and non-human life, we miss out the opportunity to value things on their own terms" (2014: 52). E é disso que dá prova quando denuncia a perfídia da utilização do objetivo numérico em estudos como a defesa, por W. Kip Viscusi, do apoio estatal ao consumo de tabaco, pela poupança de apoios à velhice pela morte precoce de fumadores ou ainda o estudo por Paul Carlin e Robert Sandy do valor financeiro do tempo gasto diariamente pelos pais na colocação das crianças em segurança rodoviária em contraste com a probabilidade de acidente (cf. 2014: 51).

A pletora de temáticas e de dados utilizados para a análise que faz em Cheaponomics permite não o delinear estável de uma panaceia, mas antes a apresentação avançar de múltiplas ideias possíveis. Como diz autor, "[c]onsider this book as a food stockpile of sorts, of alternative ideas to nourish collective action" (2014: 14). Bem ao tom americano, Carolan recorda que não há almoços grátis, e revela os custos escondidos da aposta na economia da pechincha e a centralidade do indivíduo na definição do futuro: "We are all, to some degree, responsible for this (which also means we can change things!)." (2014: 66). No entanto, avisa quanto ao perigo de se colocar a solução do mundo nas costas do consumidor individual e das suas escolhas diárias, fugindo-se assim a grandes decisões políticas colectivas e mesmo sustentar a continuidade dos erros do sistema (cf. 2014: 74-5), ao mesmo tempo que denuncia o discurso justificativo e quase sacralizante do estado actual de coisas (cf. 2014: 103). Como professor e como autor, repete o mantra de que, quando somos apanhados a fazer as perguntas erradas, é fácil darem-nos respostas que nada mudam e por isso mesmo aposta na informação como método para colocar perguntas simultaneamente informadas e disruptivas. As respostas são muitas vezes controversas, quer nas dez sugestões finais (Chapter 10. Ten Recommendations for the Good, Affordable, and Affording), quer na ideia de uma terceira via (termo por demais perigoso) entre o mercado 
e o governo (cf. 2014: 169), mas esse derrubar das falsas inevitabilidades da reflexão social é o objetivo maior de Michael Carolan. O seu trabalho continua, como provam as continuadas publicações, mas desde 2014 que o testemunho da informação foi passado ao consumidor que o lê, ao leitor que consome. E, para Carolan, o conhecimento responsabiliza. "It is time to rethink things" (2014: 126). 